Erratum

\title{
Erratum for Blamey, N.J.F., et al. The Hydrothermal Fluid Evolution of Vein Sets at the Pipeline Gold Mine, Nevada. Minerals 2017, 7, 100; doi:10.3390/min7060100
}

\author{
Nigel J. F. Blamey ${ }^{1,2, *}$, Andrew R. Campbell ${ }^{1}$ and Matt T. Heizler ${ }^{1}$ \\ 1 Department Earth and Environmental Science, New Mexico Institute of Mining and Technology, \\ 801 Leroy Place, Socorro, NM 87801, USA; campbell@nmt.edu (A.R.C.); matt@nmt.edu (M.T.H.) \\ 2 Department Earth Sciences, Western University, London, ON N6A 5B7, Canada \\ * Correspondence: nigel.blamey@nmt.edu; Tel.: +1-519-661-2111
}

Received: 13 September 2017; Accepted: 13 September 2017; Published: 20 September 2017

The authors wish to make the following corrections to the main text in the published paper [1]:

Dr. Barker's diligence points out that sample NB-84 is not an exact match for the data presented in the article of Hickey et al., Economic Geology 2014, 109, 1431-1460, doi:10.2113/econgeo.109.5.1431. The original sentence in our publication [1] on page 22 line 9 which stated, "The $\delta^{13} \mathrm{C}$ and $\delta^{18} \mathrm{O}$ values for NB-84 are an exact match for many isotopic values [59]", should be changed to, "The $\delta^{13} \mathrm{C}$ and $\delta^{18} \mathrm{O}$ values for NB-84 plot close to the range of points defined by Hickey et al. (2014) [59]".

In response to the statement, "Our paper (Hickey et al., Economic Geology 2014, 109, 1431-1460, doi:10.2113/econgeo.109.5.1431), which was cited as reference 59 in the Blamey's article [1] is quoted as 'having grouped all the calcite veins together'", we concede that the word "grouped" may not be the best choice. We would like to change the sentence on page 22 lines 10-12 which states, "Whereas they [59] group all the calcite veins together, we recognize that the white calcite stockwork and vuggy calcite veins are temporarily separate, with contrasting gas chemistries and are not coeval", to, "The Hickey et al. [59] data were undifferentiated with respect to paragenesis whereas we recognize that the white calcite stockwork and vuggy calcite veins are temporarily separate, with contrasting gas chemistries and are not coeval".

\section{Reference}

1. Blamey, N.J.F.; Campbell, A.R.; Heizler, M.T. The Hydrothermal Fluid Evolution of Vein Sets at the Pipeline Gold Mine, Nevada. Minerals 2017, 7, 100. [CrossRef] 